BMJ Open

Sport \&

Exercise

Medicine

\title{
Procollagen markers in microdialysate can predict patient outcome after Achilles tendon rupture
}

\author{
Md Abdul Alim, ${ }^{1}$ Simon Svedman, ${ }^{1}$ Gunnar Edman, ${ }^{2}$ Paul W Ackermann ${ }^{1,3}$
}

To cite: Alim MA,

Svedman S, Edman G, et al. Procollagen markers in microdialysate can predict patient outcome after Achilles tendon rupture. BMJ Open Sport Exerc Med 2016;2: e000114. doi:10.1136/ bmjsem-2016-000114

- Prepublication history and additional material is available. To view please visit the journal (http://dx.doi.org/ 10.1136/bmjsem-2016000114).

Accepted 22 May 2016

CrossMark

\footnotetext{
${ }^{1}$ Integrative Orthopedic Laboratory, Department of Molecular Medicine and Surgery, Karolinska Institutet, Stockholm, Sweden

${ }^{2}$ Department of Psychiatry, Tiohundra AB, Norrtälje,

Sweden

${ }^{3}$ Department of Orthopedics, Karolinska University Hospital, Stockholm, Sweden

Correspondence to Dr Paul W Ackermann; paul. ackermann@karolinska.se
}

\section{ABSTRACT}

Objective: Patients who sustain acute Achilles tendon rupture (ATR) exhibit variable and mostly impaired long-term functional, and patient-reported outcomes. However, there exists a lack of early predictive markers of long-term outcomes to facilitate the development of improved treatment methods. The aim of this study was to assess markers of tendon callus production in patients with ATR in terms of outcome, pain, and fatigue.

Study design and setting: Prospective cohort study; level of evidence 2. Outpatient orthopaedic/sports medicine department.

Patients: A total of 65 patients (57 men, 8 women; mean age $41 \pm 7$ years) with ATR were prospectively assessed.

Assessments: Markers of tendon callus production, procollagen type I N-terminal propeptide (PINP) and procollagen type III N-terminal propeptide (PIIINP), were assessed 2 weeks postoperatively using microdialysis followed by enzymatic quantification. Normalised procollagen levels (n-PINP and n-PIIINP) were calculated as the ratio of procollagen to total protein content. Pain and fatigue were assessed at 1 year using reliable questionnaires Achilles tendon Total Rupture Score (ATRS).

Results: Patients exhibited fatigue (77.6\%) and pain $(44.1 \%)$ to some extent. Higher levels of $n$-PINP $(R=0.38, p=0.016)$ and $n$-PIIINP ( $R=0.33, p=0.046)$ were significantly associated with less pain in the limb. Increased concentrations of PINP ( $R=-0.47, p=0.002$ ) and PIIINP $(R=-0.37, p=0.024)$ were related to more self-reported fatigue in the leg. The results were corroborated by multiple linear regression analyses.

Conclusions: Assessment of procollagen markers in early tendon healing can predict long-term patientreported outcomes after ATR. These novel findings suggest that procollagen markers could be used to facilitate the development of improved treatment methods in patients who sustain ATR.

Trial registration numbers: NCT01317160: Results. NCT02318472: Pre-results.

\section{INTRODUCTION}

After an acute Achilles tendon rupture (ATR), the healing process is prolonged, the outcome is variable, and 1 year after the

\section{What are the new findings?}

- A majority of the patients sustaining an ATR reported fatigue and/or pain in the limb at 1-year postoperative control.

- This study reports for the first time that tendon callus formation markers assessed during early tendon healing can predict the long-term patientreported outcome after an ATR.

- These novel results should be used to hasten the development of improved treatment methods for patients with tendon injuries.

rupture many patients still report pain and fatigue in the affected limb. ${ }^{1-3}$ One reason for the difficulties in improving the intervention and treatment of ATR is a lack of early markers that can be used to predict the healing progress and the long-term outcome. ${ }^{4}$

During the last decade, a method to assess the healing progression of ATR was developed by using a microdialysis technique, ${ }^{5}$ in which a small catheter is placed in the metabolically active part of the tendon, that is, the paratenon. ${ }^{6}$ Microdialysis of the extracellular matrix followed by the quantification of a wide variety of molecules of interest has provided reliable and usable data concerning metabolism and healing progress in many human tissues. 8

Two markers of collagen metabolism, procollagen type III N-terminal propeptide (PIIINP) and procollagen type I N-terminal propeptide (PINP), have been used in bone tissue for the early prediction of the success of interventions, for example, for osteoporosis treatment. ${ }^{9}$ Procollagen type I and III are essential building blocks in all types of connective tissue, and the markers PINP and PIIINP have been used to assess collagen metabolism in intact human Achilles tendons subjected to exercise and growth factor stimulation. ${ }^{10}$

To the best of our knowledge, PINP and PIIINP assessments on healing tendons have 
not been previously evaluated in terms of patient outcome. Therefore, we hypothesised that the local collagen metabolism during early human Achilles tendon (AT) repair might be associated with the long-term functional and patient-reported outcome of pain and fatigue after ATR. Pain and fatigue are two important and independent patient-reported outcome measurements (PROMs) which were considered as the primary outcomes in this study.

To study these issues, we recruited patients with acute ATR and operated on them; then at 2-week postoperatively, we performed microdialysis of the healing and contralateral intact Achilles tendons followed by enzymatic quantification to assess callus production. We assessed functional and patient-reported outcomes after 1 year.

\section{MATERIALS AND METHODS}

Patients: Patients from two different cohorts with acute ATR included in prospective, randomised controlled trials (NCT01317160 and NCT02318472) ${ }^{11}$ were analysed 2 weeks postoperatively using microdialysis $(n=65)$ and at 1 year postrupture, they were assessed using patient-reported and functional outcome measurements (table 1).

The inclusion criteria were: (1) acute unilateral ATR and (2) age between 18 and 71 years. The exclusion criteria were: inability to give informed consent; current anticoagulation treatment; planned follow-up at another hospital; inability to follow instructions; known kidney failure; heart failure with pitting oedema; thrombophlebitis; thromboembolic event during the previous 3 months; other surgery during the previous month; known malignancy; haemophilia; and pregnancy.

Surgical procedure: Patients were operated in the prone position without the use of a tourniquet on an outpatient basis. Local anaesthesia was infiltrated with $20 \mathrm{~mL}$ of Marcaine-Epinephrine $5 \mathrm{mg} / \mathrm{mL}+5 \mu \mathrm{g} / \mathrm{mL}$ (AstraZeneca, London, UK). A longitudinal $5-10 \mathrm{~cm}$ skin incision was made over the medial border of the AT, and the paratenon was incised in the midline. The tendon stumps were end-to-end sutured using a modified Kessler suture technique with two 1-0 polydioxanone (PDS II) sutures. Thereafter, the paratenon and fascia cruris were separately sutured using 3-0 Vicryl, and the skin was closed with 3-0 Ethilon. All sutures were supplied by Ethicon, Somerville, New Jersey, USA.

\begin{tabular}{ll} 
Table 1 & Patient characteristics $(\mathrm{N}=65)$ \\
\hline Variables & Descriptive statistics \\
\hline Gender: male \% (N) & $88(57)$ \\
Age in years $\mathrm{M} \pm \mathrm{SD}$ & $41 \pm 7$ \\
Height in cm M $\pm \mathrm{SD}$ & $179 \pm 7.4$ \\
Weight in $\mathrm{kg} \mathrm{M} \pm \mathrm{SD}$ & $82.2 \pm 13.0$ \\
$\mathrm{BMl}$ in $\mathrm{kg} / \mathrm{m}^{2} \mathrm{M} \pm \mathrm{SD}$ & $25.4 \pm 3.0$ \\
Smoker \% (N) & $9(6)$ \\
\hline BMl, body mass index; M, mean; N, number of patients.
\end{tabular}

After the surgery was completed, the patients were randomised and underwent 2 weeks of postoperative rehabilitation with either calf intermittent pneumatic compression beneath a weight bearing orthotic device, initially with three wedges, Aircast XP Walker, DJO LLC, Vista, California, USA $(\mathrm{n}=14),{ }^{11}{ }^{12}$ non-weight-bearing plaster cast treatment $(\mathrm{n}=19)$, or treatment with a weight-bearing orthotic device, VACOped, OPED Gmbh, Germany $(\mathrm{n}=32){ }^{11}$

At 2 weeks, all patients who returned for follow-up were mobilised with an orthosis (Aircast XP Walker, DJO LLC, Vista, California, USA ( $\mathrm{n}=23$ ) or VACOped, OPED Gmbh, Germany $(n=42))$, and were instructed to start bearing their full weight. At 6 weeks, the brace was removed.

All eligible participants received standardised information about the trial, and gave written informed consent to participate in the study. The study was approved by the Regional Ethical Review Committee in Stockholm, Sweden, 2009/2079-31/2, 2013/1791-31/3.

\section{Microdialysis}

To assess tendon healing, microdialysis followed by procollagen and protein analyses were performed as described by Greve et al. ${ }^{6}$ Microdialysis was conducted at the 2-week postoperative control. The participants were instructed not to eat, smoke or use snuff for at least 1 hour before the appointment. Only six participants were smokers (table 1 ).

A microdialysis catheter (CMA 71; CMA Microdialysis $\mathrm{AB}$, Solna, Sweden; $100 \mathrm{kDa}$ molecular cut-off, $0.5 \mathrm{~mm}$ outer diameter; $30 \mathrm{~mm}$ in length) was introduced, with guidance from ultrasound, into the peritendinous space 2-5 mm ventral to the AT. Perfusion fluid (Macrodex) was pumped at $1.0 \mu \mathrm{L} / \mathrm{min}$ (CMA 107; CMA Microdialysis, Solna, Sweden) through the catheter and was finally collected in a vial (Microvial, CMA Microanalysis AB, Solna, Sweden). Samples were collected every $30 \mathrm{~min}$ for 2 hours, and were analysed using an ISCUS Clinical Microdialysis Analyzer (CMA Microdialysis AB, Solna, Sweden). Owing to the lingering effects of the insertion trauma and the possible differences in fluid pump adjustment during the first few minutes, the first of the four vials was not considered reliable and therefore was not included in the calculations.

\section{Determinations of procollagen I and III and of protein content}

In order to assess markers of callus production, the PINP, the PIIINP, and the protein content were quantified in the microdialysis dialysate. The PINP and PIIINP levels were measured via a sandwich ELISA kit as per the manufacturer's instructions (USCN Life Science, Inc, Houston, Texas, USA) and the total protein content was assessed with the Bradford protein assay. Newly synthesised or partially processed forms of procollagens were measured as PINP and PIIINP, which are the 
soluble propeptides of collagen I and III. The qualitative, normalised procollagen levels (n-PINP and n-PIIINP) were calculated by dividing the concentrations of PINP and PIIINP, respectively, by the total protein content. ${ }^{13}$

\section{Patient-reported outcome and physical activity}

The patients' symptoms and physical activity level were assessed using two reliable and valid scores, the Achilles tendon Total Rupture Score (ATRS) ${ }^{14}$ and the Physical Activity Scale (PAS). ${ }^{15}$ The ATRS consists of 10 questions that can be scored from 0 to 10 , leading to a total summed score of $0-100$; a lower score indicates more symptoms and greater limitation of physical activity and quality of life. The ATRS includes specific questions about pain (Q4: Are you limited due to pain in your calf/AT/foot?) and fatigue (Q2: Are you limited due to fatigue in your calf/AT/foot?), which are the two important and independent PROMs that were considered as the primary outcome in this study. For the PAS, a score of 1 means that a patient is mostly sedentary, whereas a score of 6 means that a patient has engaged in heavy physical exercise several times per week.

\section{Functional evaluation}

Approximately 1 year after their injury, all patients returned for a functional outcome assessment. The functional evaluation consisted of muscular endurance tests and was performed as previously described. ${ }^{16}{ }^{17}$ The tests have been shown to be reliable and valid, ${ }^{18} 19$ and have frequently been used to evaluate the outcome after ATR. ${ }^{1} 217$ 20-22 All evaluations were performed by two independent physical therapists. A MuscleLab (Ergotest Technology Oslo, Norway) measurement system was used for the evaluations.

The heel-rise test for endurance was performed on one leg at a time, with the participant standing on a box with an incline of $10^{\circ}$. A metronome was used to keep a heel-rise frequency of $30 / \mathrm{min}$. The participant was instructed to go as high as possible on each heel-rise and then lower the heel to the starting position, and to perform as many heel-rises as possible. The test was terminated when the patient stopped, could not maintain the frequency, or did not perform a proper heel-rise. The number of heel-rises, the time and height of each heel-rise, the total work (the body weight $\times$ total distance) in joules, and the power (work/time) were used for data analysis.

\section{Statistical analysis}

The descriptive statistics and statistical analyses were calculated with SPSS, V.22.0. All variables were summarised with standard descriptive statistics such as the frequency, mean and SD. The Limb Symmetry Index (LSI) was defined as the ratio between the injured limb and the uninjured limb expressed as a percentage (injured/ uninjured $\times 100=$ LSI).
The outcome measurements were correlated with the markers of tendon callus production by means of a univariate analysis. If a variable or outcome was severely skewed, non-parametric Spearman's rank correlation was used. The significance level in all analyses was set at $\mathrm{p} \leq 0.05$ (two-tailed). The outcome measurements that were significantly correlated with the variables in the univariate analysis were used as the dependent variable in a linear regression (stepwise forward with an inclusion level of 0.05 ) with seven independent variables: gender, age, length, height, body mass index (BMI), treatment, and the markers of tendon callus production.

\section{RESULTS}

\section{Patient characteristics in relation to markers of tendon callus production}

The characteristics of the patients with ATR were significantly correlated with the levels of the tendon callus production markers assessed postoperatively at 2 weeks. Taller patients had lower levels of n-PIIINP in the injured AT ( $\mathrm{R}=-0.26, \mathrm{p}=0.042)$.

Age was positively associated with the concentrations of PINP ( $\mathrm{R}=0.32, \mathrm{p}=0.011)$, PIIINP ( $\mathrm{R}=0.34, \mathrm{p}=0.008$ ) and total proteins $(\mathrm{R}=0.34, \mathrm{p}=0.007)$ in uninjured $\mathrm{AT}$; gender, smoking, and BMI were not significantly related to the levels of the callus production markers in either the injured or uninjured AT.

\section{Markers of tendon callus production in relation to patient-reported outcome}

The primary outcome of this study was designated as pain and fatigue, which are the two important and independent outcome measures $(\mathrm{R}=0.12, \mathrm{p}=0.49)$ of the ATRS at the 1-year follow-up. Fatigue (0-10, where 10 represents no fatigue) was the most prevalent symptom and $54.5 \%$ of the patients scored 8 or less, and $77.6 \%$ scored 9 or less. Experience of pain was found in 23.8\% (scores of 8 or less) of the patients and in $44.1 \%$ (scores of 9 or less).

Correlation analyses between markers of callus production assessed postoperatively at 2 weeks, and pain and fatigue measured postoperatively at 1 year were significantly associated. Hence, higher levels of PINP and PIIINP in the injured AT were significantly correlated with greater fatigue in the injured limb (table 2).

Interestingly, the normalised collagen production in the injured AT at 2 weeks exhibited significant, positive correlations with the 1-year postoperative PROMs (table 2). Thus, patients with higher levels of n-PINP and n-PIIINP had significantly less pain in their affected AT (table 2).

\section{Markers of tendon callus production in relation to functional outcome}

The callus production markers, assessed at 2-week postoperatively, in the injured AT were not significantly correlated with the functional outcome at 1 year. However, 
Table 2 Correlations between tendon callus production and patient-reported outcome measures

\begin{tabular}{|c|c|c|c|c|c|c|c|c|}
\hline \multirow[b]{2}{*}{ Outcome } & \multicolumn{2}{|l|}{ PINP } & \multicolumn{2}{|c|}{ PIIINP } & \multicolumn{2}{|c|}{ Normalised PINP } & \multicolumn{2}{|c|}{ Normalised PIIINP } \\
\hline & $\mathbf{R}$ & p Value & $\mathbf{R}$ & p Value & $\mathbf{R}$ & p Value & $\mathbf{R}$ & p Value \\
\hline Fatigue (ATRS) & -0.47 & $0.002^{*}$ & -0.37 & $0.024^{*}$ & -0.19 & 0.248 & -0.02 & 0.928 \\
\hline Pain (ATRS) & 0.20 & 0.230 & -0.11 & 0.503 & 0.38 & $0.016^{*}$ & 0.33 & $0.046^{*}$ \\
\hline
\end{tabular}

${ }^{*} \mathrm{p}=\leq 0.05$; ATRS, Achilles tendon Total Rupture Score at 12 months; PIIINP, procollagen type III N-terminal propeptide; PINP, procollagen

type I N-terminal propeptide; $p$ Value, significance level; $\leq 0.05 ; R$, Pearson correlation coefficient.

since callus production in the uninjured AT was related to the patient characteristics, we hypothesised that it might also be related to the functional outcome. In fact, higher PIIINP levels in the uninjured AT were associated with impaired concentric power $(\mathrm{R}=-0.37, \mathrm{p}=0.020)$ and a lower maximum heel-rise height $(\mathrm{R}=-0.39, \mathrm{p}=0.012)$.

\section{Multiple linear regression analyses}

Multiple linear regression analyses examined the relationship between the 2-week postoperative assessment of the callus production markers and the 1-year assessment of PROMs, that is, pain and fatigue.

The multiple linear regression analyses confirmed the univariate analyses, and demonstrated that higher PINP levels in the injured AT as a single predictor $(\mathrm{R}=0.47)$ was related to greater fatigue in the affected limb $(\mathrm{F}(1,35)$

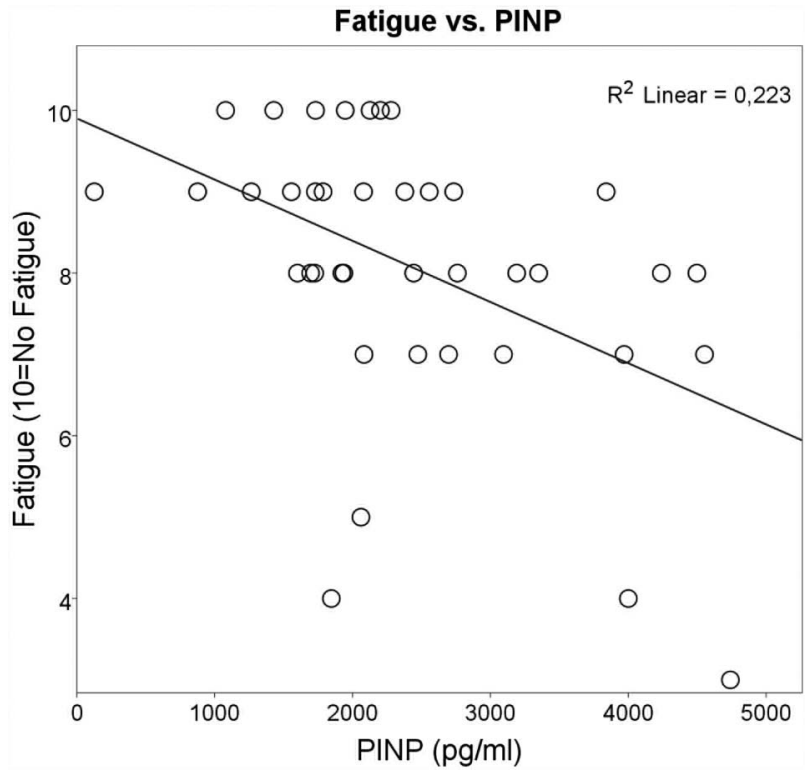

Figure 1 Each circle represents the outcome of one patient, but sometimes the circles are very close or even merge. Univariate analysis followed by regression analyses showed that a higher concentration of procollagen type I N-terminal propeptide (PINP) in the injured Achilles tendon (AT) was related to greater fatigue in the same affected $A T(R=0.47$, $\mathrm{p}=0.003$ ). The Achilles tendon Total Rupture Score (ATRS) fatigue data scale was set as $(0-10)$, where $10=$ no fatigue and $0=$ worst level of limitation. The figure also illustrates that many patients are affected by fatigue in their injured limb at 1-year follow-up.
$=9.869, \mathrm{p}=0.003, \mathbf{R}^{2}=0.22$ ) (figure 1 ). Moreover, the regression analyses corroborated that higher levels of n-PINP in the injured AT were positively associated $(\mathrm{R}=0.38)$ with the experience of less pain by patients $(\mathrm{F}(1,35)=6.019$, $\mathrm{p}=0.019, \mathrm{R}^{2}=0.15$ ) (figure 2).

Moreover, the multiple linear regression analyses verified the univariate analysis, with the finding that higher procollagen levels in the uninjured AT were correlated with a negative functional outcome when controlling for patient characteristics. Thus, higher PIIINP levels in the uninjured AT together with lower height of the patient's heel-rise predicted less concentric power $(\mathrm{F}(2,37)$ $\left.=7.63, \mathrm{p}=0.002, \mathrm{R}^{2}=0.29\right)$. Higher PIIINP levels in the uninjured AT together with the age of the patient predicted a lower maximum height of heel-rise $(F(2,37)$ $\left.=5.86, \mathrm{p}=0.006, \mathrm{R}^{2}=0.24\right)$.

Pain vs. normalized PINP

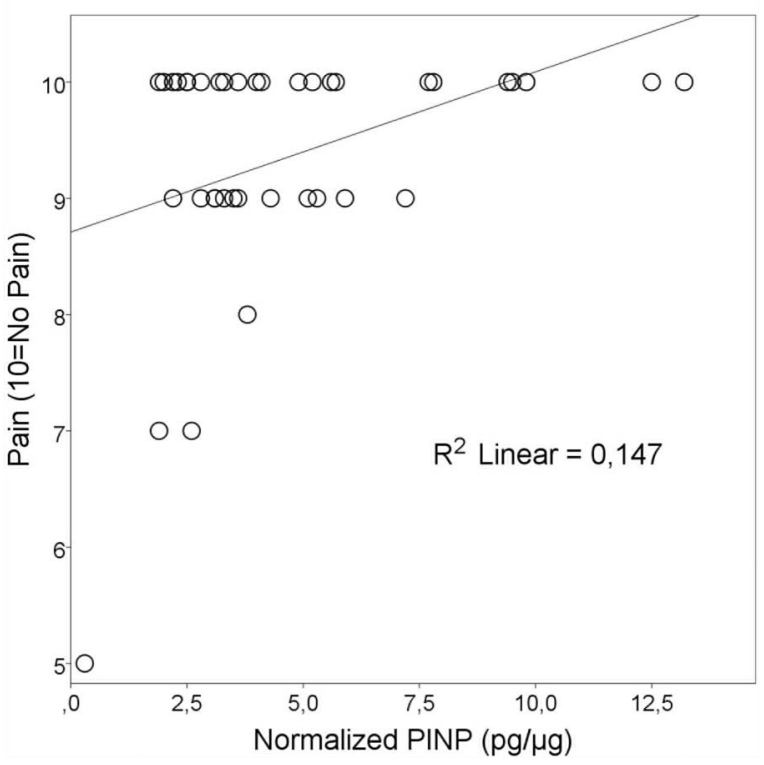

Figure 2 Each circle represents the outcome of one patient, but sometimes the circles are very close or even merge. Univariate analysis followed by regression analyses showed that elevated levels of normalised procollagen type I $\mathrm{N}$-terminal propeptide (PINP) in the injured Achilles tendon were significantly and positively correlated with less pain $(R=0.38, p=0.019)$. The Achilles tendon Total Rupture Score (ATRS) pain data scale was set as (0-10), where $10=$ no pain and $0=$ worst imaginable pain. The figure furthermore shows that many patients may exhibit some degree of pain in their injured leg at 1-year follow-up. 


\section{DISCUSSION}

This study established that assessments of the concentrations of procollagen type I and III, and total protein content in microdialysate of the healing Achilles tendons at 2 weeks after ATR can predict the patient-reported outcome of pain and fatigue at 1-year postoperatively.

The finding that more than half of the patients exhibited fatigue and/or pain at 1 year suggests that current outcome after ATR is suboptimal. The results indicating an impaired patient-reported outcome in this study are supported by several recent studies, ${ }^{20} 23$ and indicate that better methods to facilitate the development of improved treatment protocols are necessary. ${ }^{24}$

Interestingly, the data at 2-week postsurgery that demonstrate that normalised PINP and PIIINP levels were positively related to patient-reported outcome suggest that it is the qualitative ratio of collagen type I and III synthesis per gram of protein rather than the total amount of callus production that is related to an improved outcome. These findings are important for predicting the outcome in patients with ATR, and normalisation is a well-known procedure in biomedical research to compare the quantitative expression of a specific protein of interest. ${ }^{25}$ The data showing that increased levels of PINP and PIIINP were associated with impaired patientreported outcome support the above conclusions.

The multiple linear regression analyses found that the callus production markers exhibited significant independent and moderate numerical correlations with the PROMs. However, we found that the correlations between biochemical substances and PROM assessed 1 year apart should be considered as strong. Thus, these findings indicate that the levels of procollagen type I and III, and total protein content in the early healing phase of the AT could be used with other, as yet undiscovered, factors to predict the experience of pain and fatigue in the affected limb as assessed 1-year postoperatively.

The finding that callus production markers in the uninjured limb were also related to patient-reported outcome suggests that the healing response in the injured AT is not the only factor vital to the outcome. On the contrary, the data indicated that other intrinsic variables affect callus synthesis in the contralateral tendon, and can predict the patient-reported outcome. In fact, the significant correlation found between ageing and higher PINP, PIIINP, and protein values in the uninjured limb corroborate that intrinsic patient characteristics, such as age and related tendon degeneration, possibly influence PROM in the contralateral, so-called healthy AT. ${ }^{26} 27$

Therefore, patient characteristics as well as the treatment intervention were accounted for by the multiple regression analysis. The strongest correlation indicated that lower PINP values predicted less fatigue in the limb at 1 year after ATRS. The finding that higher normalised PINP was related to less experience of pain corroborated the conclusion that the procollagen markers can predict patient-related outcome, especially since pain and fatigue were found to be the two independent measurements of outcome that are important for both function and the well-being of patients with ATR.

However, the findings that lower PIIINP levels in the uninjured limb were associated with better concentric power and higher heel-rises in the injured AT suggest that a generally lower level of collagen type III synthesis is associated with better function. Earlier studies have clearly established that higher levels of collagen type III and I exist in patients with Achilles tendinopathy. ${ }^{28} 29$ Thus, higher levels of PIIINP in the uninjured AT may reflect patients exhibiting Achilles tendinopathy. In fact, Kannus and Józsa ${ }^{30}$ demonstrated in 1991 that a majority of patients who experience an ATR also show underlying degenerative changes related to Achilles tendinopathy. ${ }^{31}$ Establishing that higher levels of PINP in the injured leg were associated with a greater degree of limb fatigue suggests that the patients with higher collagen type I synthesis levels could be patients with Achilles tendinopathy.

The positive correlation of the normalised level of PINP and PIIINP in the injured AT with the patientreported outcome suggests that collagen type I and III are both important proteins in the healing process at this reparative time point. In fact, in this stage at week 2 of AT healing, fibroblast-like cells synthesise collagen type I and III which form loose connective tissue at the healing site. ${ }^{32} 33$

Similarly, in bone healing, both PINP and PIIINP have been used as markers of bone formation in response to osteoporosis therapies. ${ }^{9}$ Furthermore, baseline levels of these markers have, in other studies, also been shown to be predictive of the response to osteoporosis treatment. ${ }^{34}$ Thus, high levels of PINP have been associated with ageing and bone loss. ${ }^{9} 20$

Therefore, analogous to the situation during bone loss, we can speculate that the higher levels of PINP and PIIINP observed in our study could indicate a degenerative condition, such as tendinopathy, which would explain the negative relationship to the PROMs. On the other hand, the positive association between the normalised PINP and PIIINP at 2 -week postinjury and the patient-reported outcome suggests that qualitative collagen type I and III synthesis is important during the healing process. This hypothesis is strengthened by the notion that collagen type I and III are vital constituents of the majority of systemic restoration processes. ${ }^{35-37}$

The potential limitations include that this is a retrospective study which established potential novel predictors of ATR outcome. The results, however, need verification by prospective randomised trials. The results from this study do, furthermore, not allow any conclusion on the optimal time point to collect procollagen markers during healing as to best reflect and predict the healing response. Moreover, to what extent the degeneration, that is, tendinopathy, may affect the levels of 
procollagen I and III as well as the total protein levels are not known.

In conclusion, this cohort study established that tendon callus formation markers in a microdialysate from the paratenon of the healing AT seem to predict the patient-reported outcome at 1-year postrupture. We suggest that these markers could be used as an early screening control for new interventions and novel treatment methods, and potentially to screen patients in need of specific intervention to improve the healing outcome. Optimisation of the timing of assessment during the healing process might possibly improve the predictivity of the various procollagen markers for the outcome.

Acknowledgements This study was supported by the Swedish Research Council (project number 2012-3510), the regional agreement on medical training and clinical research (ALF) between Stockholm County Council and Karolinska Institutet (project number SLL20130150), and the Swedish National Centre for Sports Research.

Contributors MAA and PWA wrote the manuscript with potential revision. Biochemical data were generated for biochemical assessment by MAA with the help of PWA. Clinical data work and assessment was done by PWA with the help of SS and GE.

Funding Stockholm County Council and Karolinska Institutet (grant number SLL20130150), Swedish Research Council (grant number 2012-3510), and Swedish National Centre for Research in Sport (grant number P2013-0039).

Competing interests None declared.

Ethics approval The Regional Ethical Review Committee in Stockholm, Sweden.

\section{Provenance and peer review Not commissioned; externally peer reviewed.}

Open Access This is an Open Access article distributed in accordance with the Creative Commons Attribution Non Commercial (CC BY-NC 4.0) license, which permits others to distribute, remix, adapt, build upon this work noncommercially, and license their derivative works on different terms, provided the original work is properly cited and the use is non-commercial. See: http:// creativecommons.org/licenses/by-nc/4.0/

\section{REFERENCES}

1. Nilsson-Helander K, Silbernagel KG, Thomeé R, et al. Acute Achilles tendon rupture: a randomized, controlled study comparing surgical and nonsurgical treatments using validated outcome measures. Am J Sports Med 2010;38:2186-93.

2. Bostick GP, Jomha NM, Suchak AA, et al. Factors associated with calf muscle endurance recovery 1 year after Achilles tendon rupture repair. J Orthop Sports Phys Ther 2010;40:345-51.

3. Olsson N, Nilsson-Helander K, Karlsson J, et al. Major functional deficits persist 2 years after acute Achilles tendon rupture. Knee Surg Sports Traumatol Arthrosc 2011;19:1385-93.

4. Schwellnus MP. Genetic biomarkers and exercise-related injuries: current clinical applications? Br J Sports Med 2013;47:530-2.

5. Bolinder J, Ungerstedt U, Arner P. Long-term continuous glucose monitoring with microdialysis in ambulatory insulin-dependent diabetic patients. Lancet 1993;342:1080-5.

6. Greve K, Domeij-Arverud E, Labruto F, et al. Metabolic activity in early tendon repair can be enhanced by intermittent pneumatic compression. Scand J Med Sci Sports 2012;22:e55-63.

7. Langberg H, Skovgaard D, Petersen LJ, et al. Type I collagen synthesis and degradation in peritendinous tissue after exercise determined by microdialysis in humans. J Physiol (Lond) 1999;521 (Pt 1):299-306

8. de la Peña A, Liu P, Derendorf H. Microdialysis in peripheral tissues. Adv Drug Deliv Rev 2000;45:189-216.

9. Eastell R, Robins SP, Colwell T, et al. Evaluation of bone turnover in type I osteoporosis using biochemical markers specific for both bone formation and bone resorption. Osteoporos Int 1993;3:255-60.
10. Vestergaard P, Jørgensen JO, Olesen JL, et al. Local administration of growth hormone stimulates tendon collagen synthesis in elderly men. J Appl Physiol (1985) 2012;113:1432-8.

11. Domeij-Arverud $E$, Labruto $F$, Latifi $A$, et al. Intermittent pneumatic compression reduces the risk of deep vein thrombosis during post-operative lower limb immobilisation: a prospective randomised trial of acute ruptures of the Achilles tendon. Bone Joint $J$ 2015;97-B:675-80.

12. Domeij-Arverud E, Latifi A, Labruto $F$, et al. Can foot compression under a plaster cast prevent deep-vein thrombosis during lower limb immobilisation? Bone Joint J 2013;95-B:1227-31.

13. Ahmad CS, Clark AM, Heilmann N, et al. Effect of gender and maturity on quadriceps-to-hamstring strength ratio and anterior cruciate ligament laxity. Am J Sports Med 2006;34:370-4.

14. Nilsson-Helander K, Thomeé R, Silbernagel KG, et al. The Achilles tendon Total Rupture Score (ATRS): development and validation Am J Sports Med 2007;35:421-6.

15. Grimby G. Physical activity and muscle training in the elderly. Acta Med Scand Suppl 1986;711:233-7.

16. Silbernagel KG, Gustavsson A, Thomeé R, et al. Evaluation of lower leg function in patients with Achilles tendinopathy. Knee Surg Sports Traumatol Arthrosc 2006;14:1207-17.

17. Silbernagel KG, Nilsson-Helander K, Thomeé $R$, et al. A new measurement of heel-rise endurance with the ability to detect functional deficits in patients with Achilles tendon rupture. Knee Surg Sports Traumatol Arthrosc 2010;18:258-64.

18. Möller M, Lind K, Styf J, et al. The reliability of isokinetic testing of the ankle joint and a heel-raise test for endurance. Knee Surg Sports Traumatol Arthrosc 2005;13:60-71.

19. Svantesson $\mathrm{U}$, Carlsson U, Takahashi $\mathrm{H}$, et al. Comparison of muscle and tendon stiffness, jumping ability, muscle strength and fatigue in the plantar flexors. Scand J Med Sci Sports 1998;8 (Pt 1):252-6.

20. Olsson N, Petzold M, Brorsson A et al. Predictors of clinical outcome after acute Achilles tendon ruptures. Am J Sports Med 2014;42:1448-55

21. Silbernagel KG, Thomeé R, Eriksson $\mathrm{Bl}$, et al. Continued sports activity, using a pain-monitoring model, during rehabilitation in patients with Achilles tendinopathy - a randomized controlled study. Am J Sports Med 2007;35:897-906.

22. Todorov A, Schaub F, Blanke F, et al. Clinical assessment is sufficient to allow outcome evaluation following surgical management of Achilles tendon ruptures. Muscles Ligaments Tendons J 2015;5:68-72.

23. McCormack R, Bovard J. Early functional rehabilitation or cast immobilisation for the postoperative management of acute Achilles tendon rupture? A systematic review and meta-analysis of randomised controlled trials. Br J Sports Med 2015;49:1329-35.

24. Freedman BR, Gordon JA, Soslowsky LJ. The Achilles tendon: fundamental properties and mechanisms governing healing. Muscles Ligaments Tendons J 2014;4:245-55.

25. Kaushik P, Molinelli EJ, Miller ML, et al. Spatial normalization of reverse phase protein array data. PLoS ONE 2014;9:e97213.

26. Tompra N, van Dieën JH, Coppieters MW. Central pain processing is altered in people with Achilles tendinopathy. $\mathrm{Br} J$ Sports Med Published Online First: 23 Dec 2015 doi:10.1136/bjsports-2015095476

27. Oliva F, Piccirilli E, Berardi AC, et al. Hormones and tendinopathies: the current evidence. Br Med Bull 2016;117:39-58.

28. de Mos M, van El B, DeGroot J, et al. Achilles tendinosis: changes in biochemical composition and collagen turnover rate. Am J Sports Med 2007;35:1549-56.

29. Pingel J, Petersen MC, Fredberg U, et al. Inflammatory and metabolic alterations of Kager's Fat Pad in chronic Achilles tendinopathy. PLOS ONE 2015;10:e0127811.

30. Kannus $P$, Józsa L. Histopathological changes preceding spontaneous rupture of a tendon. A controlled study of 891 patients. J Bone Joint Surg Am 1991;73:1507-25.

31. Tallon C, Maffulli N, Ewen SW. Ruptured Achilles tendons are significantly more degenerated than tendinopathic tendons. Med Sci Sports Exerc 2001;33:1983-90.

32. Carlsson $\mathrm{O}$, Schizas N, Li J, et al Substance $\mathrm{P}$ injections enhance tissue proliferation and regulate sensory nerve ingrowth in rat tendon repair. Scand J Med Sci Sports 2011;21:562-9.

33. Ackermann PW. Tendinopathy-understanding epidemiology, pathology, healing, and treatment. In: Gomes ME, Reis RL, Rodrigues MT, eds. Tendon regeneration: Elsevier, 2015: 113-28.

34. NIH Consensus Development Panel on Osteoporosis Prevention Da and Therapy. Osteoporosis prevention, diagnosis, and therapy. JAMA 2001;285:785-95. 
35. Delmas PD, Stenner D, Wahner HW, et al. Increase in serum bone gamma-carboxyglutamic acid protein with aging in women. Implications for the mechanism of age-related bone loss. J Clin Invest 1983;71:1316-21.

36. Eriksen EF, Hodgson SF, Eastell R, et al. Cancellous bone remodeling in type I (postmenopausal) osteoporosis: quantitative assessment of rates of formation, resorption, and bone loss at tissue and cellular levels. J Bone Miner Res 1990 5:311-19.

37. Uebelhart D, Schlemmer A, Johansen JS, et al. Effect of menopause and hormone replacement therapy on the urinary excretion of pyridinium cross-links. J Clin Endocrinol Metab 1991;72:367-73. 